\title{
Fluid Identification Based on NMR Apparent Free Water Porosity Inversion: A Case Study of Paleozoic Tight Sandstone Gas Reservoirs in Western Ordos
}

\author{
Fuqiang Lai, ${ }^{1}$ Yuejiao Liu $\mathbb{D}^{1},{ }^{1}$ Xiaopan Kou, ${ }^{2}$ Zhaohui Huang, ${ }^{1}$ Zhen Chen, ${ }^{2}$ Yuanqi Liu, ${ }^{1}$ \\ Guoqiang Jiang, ${ }^{1}$ Yongqian Zang, ${ }^{1}$ Min Wang, ${ }^{3}$ and Ruyue Wang $\mathbb{\oplus}^{4}$ \\ ${ }^{1}$ Chongqing Key Laboratory of Complex Oilfield Exploration and Development, Chongqing University of Science and Technology, \\ Chongqing 401331, China \\ ${ }^{2}$ Exploration and Development Research Institute of Changqing Oilfield Company, Xi'an 710021, China \\ ${ }^{3}$ SINOPEC Exploration and Development Research Institute of Shengli Oilfield Company, Beijing, Shandong 257000, China \\ ${ }^{4}$ SINOPEC Petroleum Exploration and Production Research Institute, Beijing 100083, China
}

Correspondence should be addressed to Yuejiao Liu; 523029007@qq.com

Received 8 October 2021; Accepted 7 January 2022; Published 27 January 2022

Academic Editor: Martina Zucchi

Copyright (C) 2022 Fuqiang Lai et al. This is an open access article distributed under the Creative Commons Attribution License, which permits unrestricted use, distribution, and reproduction in any medium, provided the original work is properly cited.

\begin{abstract}
Tight sandstone reservoirs are affected by various factors such as pore structure, formation water salinity, and siliceous cementation, which lead to the abnormal phenomenon of high-resistivity water layers and increase the difficulty in identifying gas and water layers by conventional logging. In this study, the pore types and pore size distribution characteristics of tight sandstone reservoirs were firstly determined by NMR and high-pressure mercury injection experiments, and then the iterative least-square method was used to automatically optimize the inversion method of pseudo-capillary pressure curve and search for the optimal conversion coefficient. Finally, the apparent free water porosity was inversed and the fluid identification standard was obtained and applied. The results showed that the reservoirs mainly developed intergranular pores, cutting solution pores, and intergranular pores. The pore throats were poorly sorted, and the displacement pressure was high. The median radius ranged from 0.01 to $0.48 \mu \mathrm{m}$, and the main peak range was from 0.02 to $0.06 \mu \mathrm{m}$. Pores were of mainly small-hole fine throat type. In the inversion results of the optimal conversion coefficient, the correlation coefficient between the aperture parameters and the results of highpressure mercury injection experiments was greater than 0.93 . According to the fluid property identification standard based on nuclear magnetic apparent free water porosity, the high-resistivity water layers were effectively identified and its coincidence rate with the final field test was $10.7 \%$ higher than that of the conventional method. This identification method can be used to identify complex fluids in tight sandstone reservoirs.
\end{abstract}

\section{Introduction}

The P2h formation and P1s formation of the Upper Paleozoic Permian in Tianhuan Sag belong to typical tight sandstone reservoirs in China $[1,2]$. The water layers in the area have no unified gas-water interface, and disconnected water bodies are distributed in the area $[3,4]$. In addition, high formation water salinity, siliceous cementation, highresistivity minerals in pores, and other factors $[5,6]$ lead to the high resistivity of reservoirs and water layers. Therefore, it is difficult to identify gas and water layers with conventional logging data.

In this study, the identification method of high-resistivity water layers was developed through the combination of nuclear magnetic logging data and high-pressure mercury injection experiments. Firstly, it is necessary to calculate the pseudo-capillary pressure curve, reservoir pore structure parameters, and pore size spectrum with nuclear magnetic logging data. The calculation method of the pseudo-capillary pressure curve has been extensively explored [7-10]. Shao 
et al. [11] calculated the pseudo-capillary pressure curve with the two-dimensional sectional area method and improved the fitting effect of macropores. However, the high-pressure mercury injection measurements adopted in this method could only reflect connected pores, whereas the nuclear magnetic resonance logging (NMR) data could reflect the total pores. As a result, the pseudo-pore size distribution curve calculated with nuclear magnetic resonance logging data and the pore size distribution curve measured with core data are different in the pore size distribution position and pore shape. Based on the similarity comparison method, Liu et al. [12] transformed the $T_{2}$ spectrum integral curve of nuclear magnetic resonance logging data into the nuclear magnetic capillary pressure curve. This transformation method provided only simple mathematical statistical results without theoretical basis and adopted the same linear conversion scale coefficient for all types of core samples, thus resulting in poor fitting results in small apertures. Wang et al. [13] analyzed the sectional area method and similarity comparison method, adopted different methods to separately fit various reservoirs with different quality, and achieved the better fitting results of large and small pores. However, in this method, it is necessary to artificially judge the reservoir quality based on porosity and permeability parameters. The method has strong subjectivity and depends on the regional core experiment statistics, so it is not suitable for new blocks or new exploration wells.

Based on the previous methods [13-16], with the iterative least-square method, the conversion coefficient corresponding to the minimum area difference and the maximum correlation coefficient was iteratively and automatically searched to calculate the pseudo-capillary pressure curve in the study. Based on the absolute error between the pseudo-capillary pressure curve and the core capillary pressure curve, the inversion method of the pseudo-capillary pressure curve was optimized. The statistical result of the absolute errors of $N$ rock samples was obtained, and the average conversion coefficient of $W$ group with the minimum absolute error was used as the regional optimal conversion coefficient. Then, the optimal pseudo-capillary pressure curve was used to calculate the nuclear magnetic porosity and pore structure parameters. Then, the capillary bound water porosity and free water porosity were determined by the comprehensive analysis of gas test data, maximum pore throat radius, nuclear magnetic porosity, and clay bound water porosity. Finally, with the apparent free water porosity and deep lateral porosity, the crossplot was prepared to determine the gas-water division criteria and identify gas reservoirs and high-resistivity water layers. This method utilized the sectional area method and similarity comparison method more comprehensively. It could automatically search for the optimal conversion coefficient and calculate the pseudo-capillary pressure curve in real time without artificially dividing the reservoir quality, thus avoiding the errors caused by subjective factors to a certain degree. The complex fluid identification parameters required in traditional fluid identification methods are converted into the apparent free water porosity in the study.

\section{Regional Geological Background}

The study area is located in Qingshimao and Gaoshawo regions in the northern section of Tianhuan Sag, Ordos Basin. It is close to the thrust belt on the western margin and the Northern Shaanxi Slope, and Sugri Gas Field is located in the southeast of the study area (Figure 1). The Upper Paleozoic in Tianhuan Sag is the sedimentary system composed of a set of marine-continental transitional facies and develops $\mathrm{C} 2 \mathrm{~b}$ formation, $\mathrm{P} 1 \mathrm{t}$ formation, $\mathrm{P} 1 \mathrm{~s}$ formation, $\mathrm{P} 2 \mathrm{~h}$ formation, and P2s formation from bottom to top $[3,17,18]$. In the study area, large stable regional slopes formed since the Paleozoic Era provide good structural conditions for the formation of natural gas. The channel sand bodies of P1s formation and $\mathrm{P} 2 \mathrm{~h}$ formation are the main gas-producing sections, and the sand bodies mainly contain lithic quartz sandstone and quartz sandstone. On gentle slopes, there are no characteristics of bottom water or edge water and even complex gas-water relations such as "gas-water inversion" are formed [19-21].

\section{Pore Structure Experiment and Analysis of Tight Sandstone Reservoirs}

3.1. Pore Structure Characterization Experiments. An argon ion scanning electron microscope (FE-SEM) was used for the qualitative characterization of pores [22]. According to the scanning electron microscope analysis method of rock samples in SY/T5162-2014, the samples were placed in polishing instrument (JEOL, IB-09010CP), polished for about $10 \mathrm{~h}$ to obtain a polished surface $(1000 \mu \mathrm{m} \times 500 \mu \mathrm{m})$, and analyzed under a cold field emission scanning electron microscope (JEOL-JSM 7500F) equipped with an EDAX energy spectrometer.

The $\mathrm{CO}_{2} / \mathrm{N}_{2}$ adsorption and high-pressure mercury injection experiment was performed for the quantitative characterization of pore structure [23]. According to the determination method of full pore size distribution of shale in NB/T14008-2015, the mercury injection part was performed with a mercury pore tester (Micromeritics AutoPore IV 9520) and the adsorption part was completed with a specific surface and porosity meter (JW-BK22). According to the gas adsorption BET method for determining the specific surface area of solid materials in GB/t19587-2004 with the Brunauer-Emmett-Teller (BET) equation, the BET straight line diagram was plotted in the relative pressure range of 0.05 to 0.35 to obtain the BET specific surface area [24]. The pore volume characteristics were calculated using the Barret-Joyner-Halenda (BJH) method [25]. The transverse relaxation time curve of NMR technology was used to explore the pore size distribution trend. The absolute pore size was calculated by comparing the pore size distribution obtained with mercury injection method with the NMR spectrum.

3.2. Pore Structure Analysis. According to the thin section analysis and statistics of reservoir samples of sections $\mathrm{P} 2 \mathrm{x} 8$ and P1s in the study area, in the south and west of Sugri Gas Field (Figures 2 and 3), the clastic content in Section P2x8 was $83.97 \%$ and the clastic components were mainly quartz 


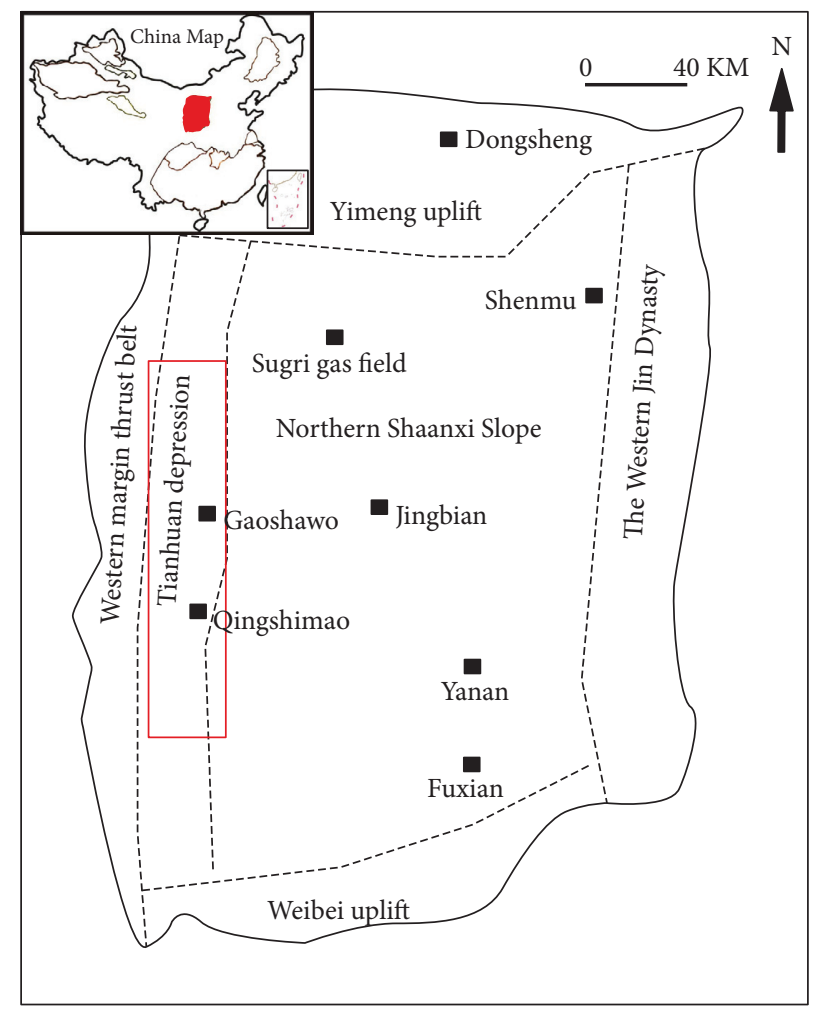

\begin{tabular}{|c|c|c|c|c|c|c|c|}
\hline \multicolumn{6}{|c|}{ Stratigraphic age } & \multirow{2}{*}{$\begin{array}{c}\text { Thicknes } \\
(\mathrm{m})\end{array}$} & \multirow{2}{*}{$\begin{array}{l}\text { Tectonic } \\
\text { stage }\end{array}$} \\
\hline \multicolumn{2}{|c|}{ Circles } & System & \multicolumn{3}{|c|}{ Group } & & \\
\hline \multirow{3}{*}{\multicolumn{2}{|c|}{ Cenozoic }} & $\mathrm{Q}$ & & & & 280 & \multirow{3}{*}{ Himalayan } \\
\hline & & $\mathrm{N}$ & & & & 1650 & \\
\hline & & $\mathrm{E}$ & & & & 970 & \\
\hline \multirow{10}{*}{\multicolumn{2}{|c|}{ Mesozoic }} & $\mathrm{K}$ & & & & 1280 & \multirow{6}{*}{ Yanshan } \\
\hline & & \multirow{5}{*}{$\mathrm{J}$} & \multicolumn{3}{|c|}{ K1y } & 1100 & \\
\hline & & & \multirow{2}{*}{\multicolumn{3}{|c|}{$\begin{array}{l}J 2 a \\
J 2 Z\end{array}$}} & 250 & \\
\hline & & & & & & 300 & \\
\hline & & & \multirow{2}{*}{\multicolumn{3}{|c|}{$\frac{J 1 y}{\mathrm{Jlf}}$}} & 300 & \\
\hline & & & & Jif & & 100 & \\
\hline & & \multirow{4}{*}{$\mathrm{T}$} & \multicolumn{3}{|c|}{$\mathrm{T} 2 \mathrm{y}$} & 1200 & \multirow{4}{*}{ Indochina } \\
\hline & & & \multicolumn{3}{|c|}{$\mathrm{T} 2 \mathrm{z}$} & 500 & \\
\hline & & & \multicolumn{3}{|c|}{ T1h } & 120 & \\
\hline & & & \multicolumn{3}{|c|}{ T11 } & 380 & \\
\hline \multirow{14}{*}{ Paleozoic } & \multirow{12}{*}{$\begin{array}{c}\text { Upper } \\
\text { Paleozoic }\end{array}$} & \multirow{11}{*}{$\mathrm{P}$} & \multicolumn{3}{|c|}{$\mathrm{P} 2 \mathrm{~s}$} & 282 & \multirow{12}{*}{ Haixi } \\
\hline & & & \multicolumn{3}{|c|}{ P2sh } & 150 & \\
\hline & & & \multirow{5}{*}{$\mathrm{P} 2 \mathrm{~h}$} & \multirow{5}{*}{$\mathrm{P} 2 \mathrm{x}$} & P2x5 & 25 & \\
\hline & & & & & $\mathrm{P} 2 \times 6$ & 25 & \\
\hline & & & & & P2x7 & 25 & \\
\hline & & & & & P2x8 & 25 & \\
\hline & & & & & $\mathrm{P} 2 \times 9$ & 30 & \\
\hline & & & & & P1s1 & 50 & \\
\hline & & & & & P1s2 & 50 & \\
\hline & & & & & P1t1 & 15 & \\
\hline & & & & & P1t2 & 20 & \\
\hline & & $\mathrm{C}$ & & $\mathrm{C} 2 \mathrm{~b}$ & & 50 & \\
\hline & Lower & $\mathrm{O}$ & & $\mathrm{O} 1 \mathrm{~m}$ & & 1400 & \\
\hline & Paleozoic & $€$ & & & & 920 & Caledonian \\
\hline & & $\mathrm{Zz}$ & & & & 180 & \\
\hline & & $\mathrm{Zj}$ & & & & $>1000$ & \\
\hline Prote & rozolc & $\overline{Z c}$ & & & & $>1000$ & Precambrian \\
\hline & & $\mathrm{Pt}$ & & & & 8000 & \\
\hline Arc & hean & $\mathrm{Ar}$ & & & & 9000 & \\
\hline
\end{tabular}

$\begin{array}{ll}\square \text { Basin boundary } & \square \text { Town } \\ \square \text { Tectonic boundary } & \square \text { Study area }\end{array}$

FIGURE 1: Geographic position and stratum subdivision of the study area.
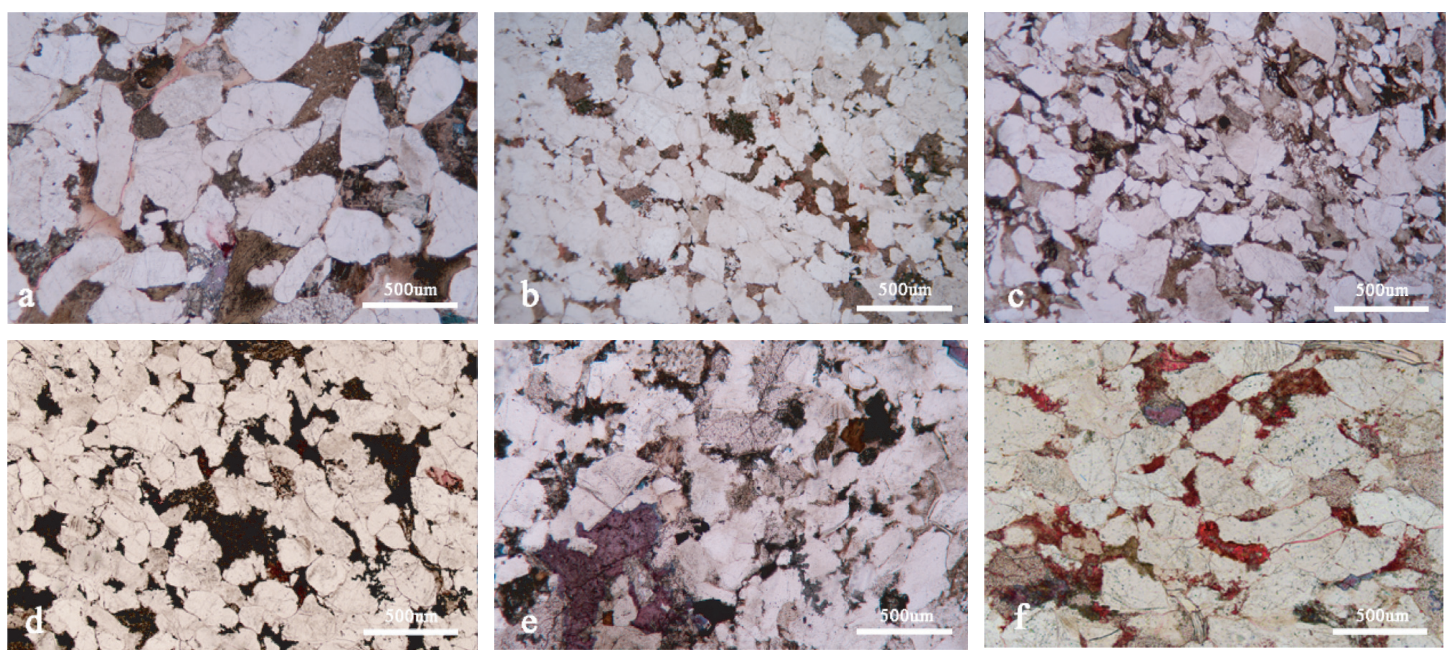

Figure 2: Analysis results of microscope images of polished thin sections in the study area. (a) Well Li40, 4038 m P2x8, intergranular pores and intracrystal pores; (b) Li46, $4225 \mathrm{~m}$ P2x8, intracrystal pores; (c) Li53, $3981 \mathrm{~m} \mathrm{P2x8}$, intergranular pores, dissolved pores, and intracrystal pores; (d) Well Li55, $3814 \mathrm{~m}$ P2x8, intergranular pores, dissolved pores, and intracrystal pores; (e) Well Li57, 3784 m P2x8, dissolved pores

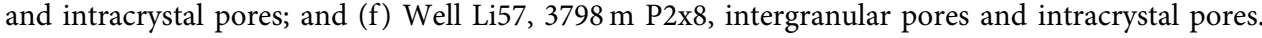

(59.56\%), rock debris (18.42\%), and feldspar (2.09\%). In Section P1s, the clastic content was $81.9 \%$ and the clastic components were mainly quartz (64.07\%), rock debris (17.59\%), and feldspar (0.25\%) (Figure 3(a)). The pores were mainly debris dissolved pores, intergranular pores, and intracrystal pores (Figure 3(b)). The lithology of the study area is mainly rock debris quartz sandstone with intergranular pores and rock debris dissolved pores.

The $T_{2}$ spectra of nuclear magnetic resonance logging data obtained from 50 samples of 23 wells such as Well L57 and Well L59 and the statistical analysis of core mercury injection experimental data are summarized below. The 


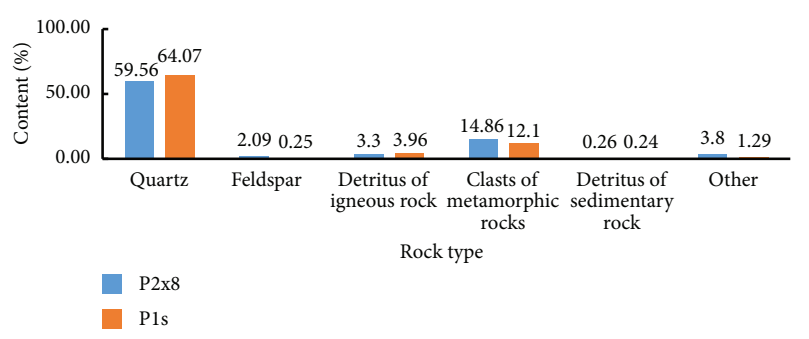

(a)

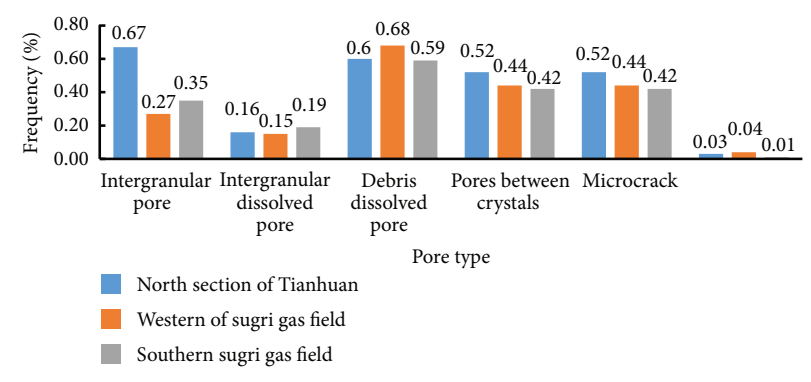

(b)

Figure 3: Statistical diagram of clastic composition and pore types of $\mathrm{H} 2 \mathrm{x} 8$ and P1s in the study area. (a) Statistical histogram of detrital composition of $\mathrm{H} 2 \mathrm{x} 8$ and PIs. (b) Statistical histogram of pore type distribution.

displacement pressure distribution range of $\mathrm{P} 2 \mathrm{x} 8$ sandstone section was 0.03 to $60 \mathrm{MPa}$ with the average of $5.73 \mathrm{MPa}$ and the main peak range of 0.5 to $1 \mathrm{MPa}$ (Figure $4(\mathrm{a})$ ). The median pore throat radius range was 0.01 to $0.48 \mu \mathrm{m}$ with the average of $0.09 \mu \mathrm{m}$ and the main peak range of 0.02 to $0.06 \mu \mathrm{m}$ (Figure 4(b)). The sorting coefficient range was 0.13 to 5.33 with an average of 2.27 and the main peak range of 1 to 4 (Figure $4(\mathrm{c})$ ). The skewness distribution range was -2.29 to 2.59 with an average of 0.61 and the main peak range of -1 to 0 and 1 to 2 (Figure $4(\mathrm{~d})$ ). The reservoir was characterized by the significant micro-heterogeneity, the poor pore throat sorting effect, the high displacement pressure, and the small median radius of throat. Throats were mainly small-hole fine throat type, thus resulting in incomplete displacement of formation water by oil and gas migration and the high content of residual formation water.

3.3. Relationships between Pore Structure, Fluid Properties, Permeability, and Productivity. Pore characteristics affect fluid properties, permeability, and gas productivity in reservoirs [26-29]. Figure 5 shows the distribution of nuclear magnetic resonance $T_{2}$ spectrum of three cores. From left to right, the proportion of small holes decreased and the proportion of large holes increased. The proportion of bound water porosity decreased, indicating that the pore structure of cores from left to right was gradually improved in turn. The sample permeability was greatly increased from $0.16 \times 10^{-3} \mu \mathrm{m}^{2}$ of the No. 16 sample to $30.441 \times 10^{-3} \mu \mathrm{m}^{2}$ of the No. 6 sample, and the gap was nearly 200 times. The difference indicated that pore structures significantly affected the reservoir seepage capacity. The better the pore structure, the higher the corresponding reservoir permeability. The comparative analysis of mercury injection test and gas test results of samples indicated that with the improvement of pore structure, gas production gradually increased and water production gradually decreased.

\section{Inversion Method of Apparent Free Water Porosity Based on NMR Logging}

According to the free water porosity inversion process (Figure 6), $N$ typical core samples with different pore sizes were selected to conduct the high-pressure mercury injection experiment and obtain the core capillary pressure curve. Then, based on the nuclear magnetic logging data, the $T_{2}$ distribution of rock samples at the corresponding depth was obtained through exponential solution and then the nuclear magnetic reverse cumulative spectrum was calculated to characterize mercury injection saturation $[13,30]$. Based on the regional reservoir characteristics, the initial boundary value between large and small apertures was set and the pseudo-capillary pressure curve was calculated in sections. Based on the capillary pressure curve in the rock core, the area difference of the capillary pressure curve and the correlation coefficient were calculated. Then, the boundary value was transformed according to the step size, and the leastsquare automatic iteration was used to search for the minimum area difference and the maximum correlation coefficient between the core capillary pressure curve and the pseudo-capillary pressure curve [31-33]. By calculating the pseudo-capillary pressure curve of each rock sample and comparing it with the core capillary pressure curve, the absolute error between the two curves was calculated. The absolute errors of all rock samples were counted, and the regional optimal conversion coefficient was found to calculate the pseudo-capillary pressure curve. The reservoir pore structure parameters and pore size spectrum were inversed with the optimal pseudocapillary pressure curve and calibrated with the experimental data of high-pressure mercury injection.

Then, the crossplot of the nuclear magnetic maximum pore throat radius calculated with the optimal pseudocapillary pressure curve, nuclear magnetic porosity, and gas test data was used to determine the lower limit of free water pore diameter. Assuming that only bound fluid existed under this lower limit, the capillary bound water porosity was calculated. With water saturation $S_{w}$ calculated by the Archie formula and the total porosity of nuclear magnetic logging, the total water content porosity $\phi_{w}$ was calculated. Clay-bound water porosity provided by NMR inversion $\phi_{c b w}$ was used to inverse free water porosity. Finally, the crossplot analysis of nuclear magnetic free water porosity, undisturbed formation resistivity, and gas test data was performed, and the gas and water discrimination standard was established with free water porosity to distinguish gas and water in tight reservoirs. 


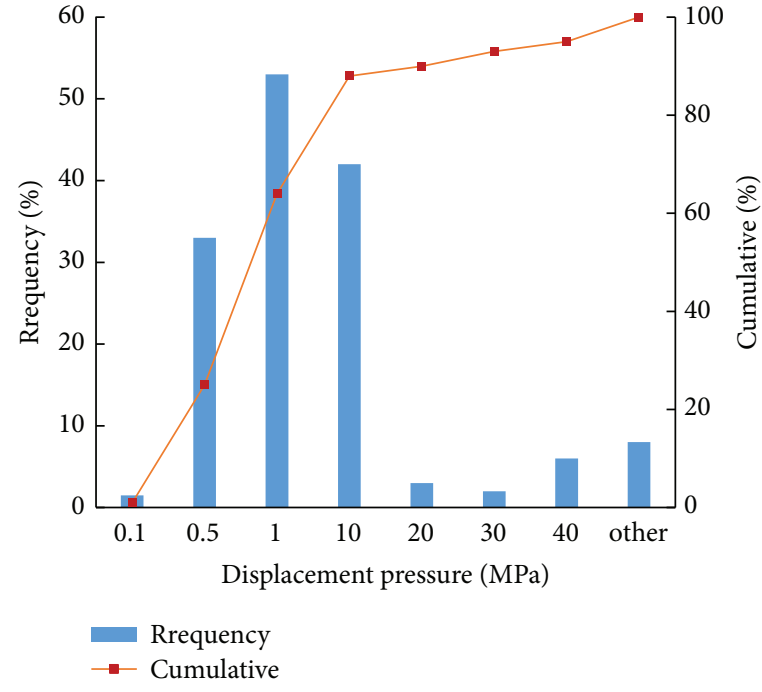

(a)

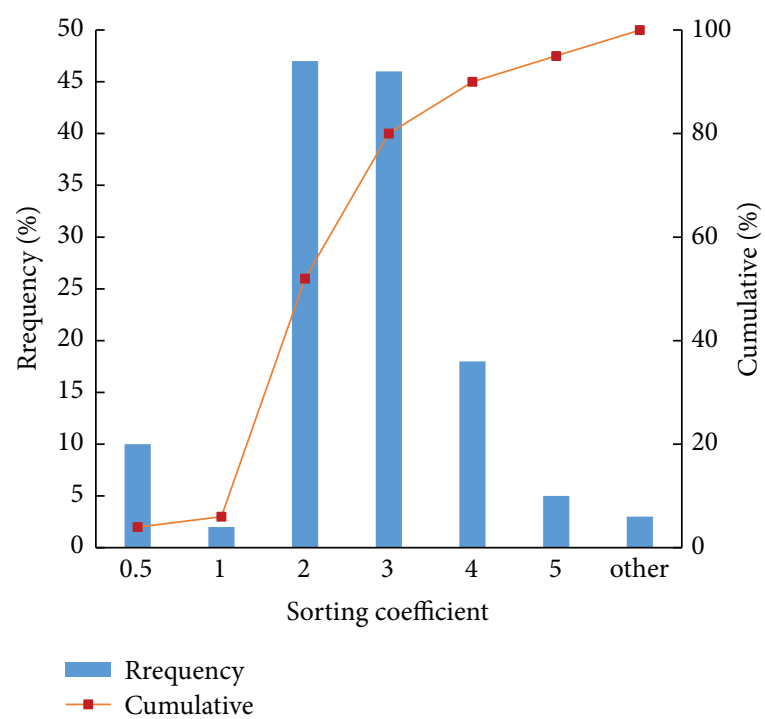

(c)

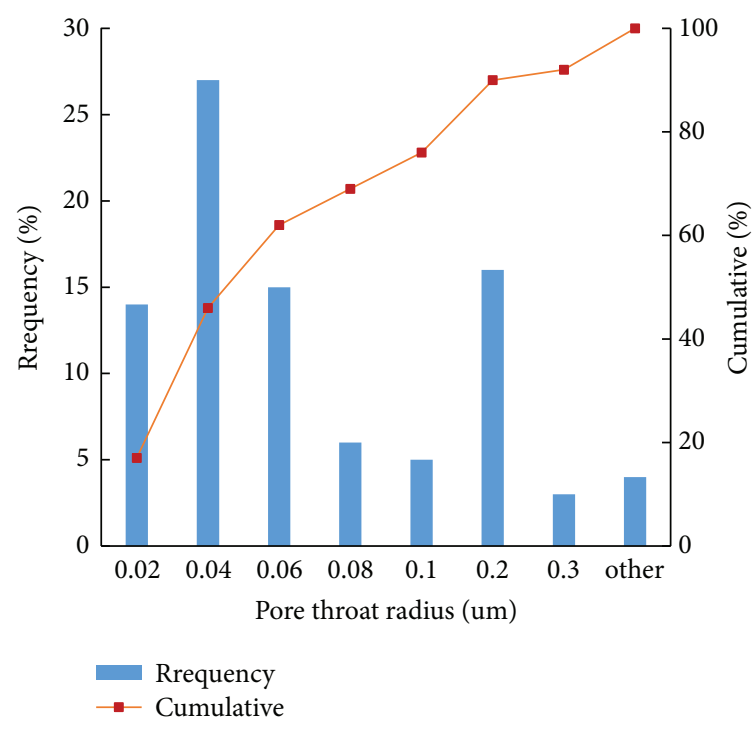

(b)

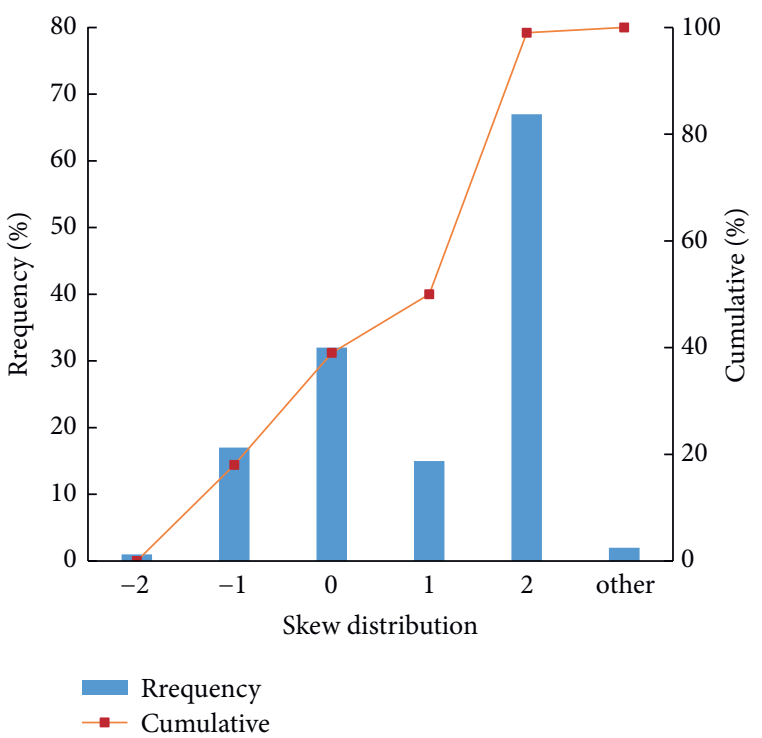

(d)

Figure 4: Statistical diagrams of pore structure parameters of the P2x8 tight sandstone reservoir in the study area. (a) P2x8 displacement histogram. (b) P2x8 histogram of median pore throat radius. (c) P2x8 sorting coefficient histogram. (d) P2x8 skew distribution histogram.

4.1. Theoretical Basis of Inversion of Pseudo-Capillary Pressure Curve from NMR Logging Data. The original data of NMR logging consist of the $T_{2}$ relaxation attenuation curve composed of hundreds of spin echoes. Through multiexponential fitting of spin echo string, the $T_{2}$ relaxation time of various types of pores and the proportion $P_{i}$ of pores in total pores can be solved from the equation of total magnetization signal $(M(t), t=1,2,3, \ldots, n)$ measured by rock NMR. This is commonly known as $T_{2}$ distribution $[34,35]$.

$$
\begin{aligned}
M(1) & =\sum_{i}^{m} P_{i} \cdot e^{t(1) / T_{2 i}}+\varepsilon(1), \\
M(2) & =\sum_{i}^{m} P_{i} \cdot e^{t(1) / T_{2 i}}+\varepsilon(2), \\
M(n) & =\sum_{i}^{m} P_{i} \cdot e^{t(1) / T_{2 i}}+\varepsilon(n), \\
t(j) & =j \cdot T_{E}, \quad j=1,2,3, \ldots, n,
\end{aligned}
$$




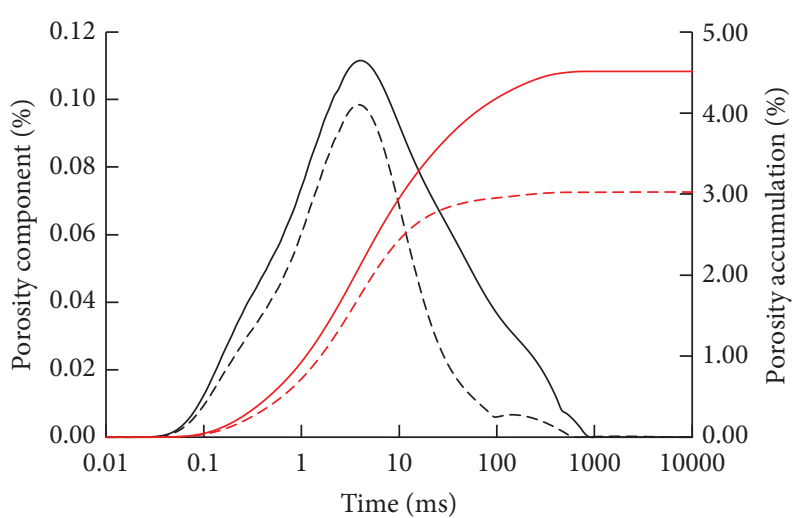

(a) No16

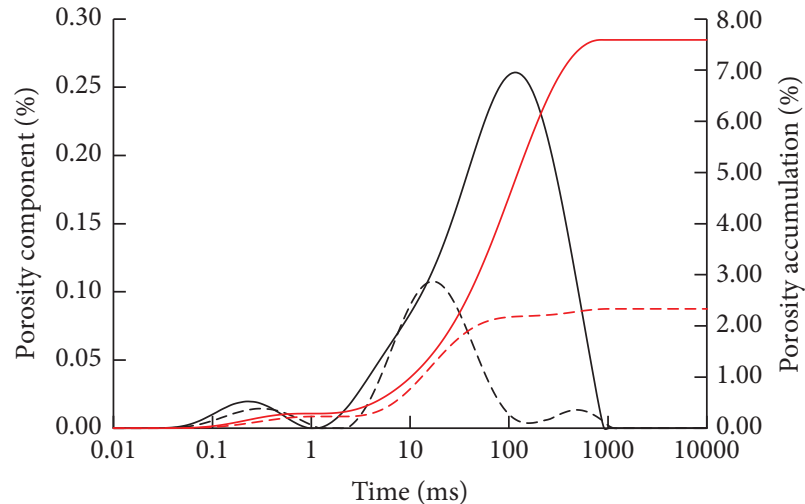

(b) No26

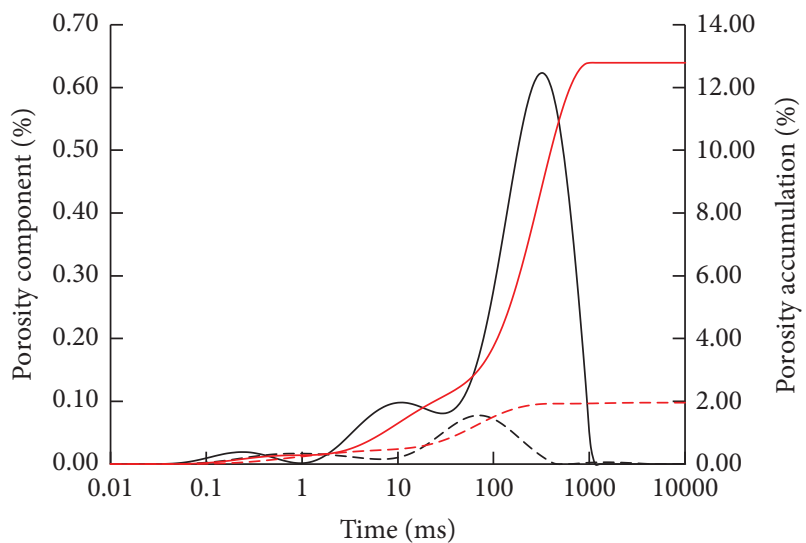

(c) No6

\begin{tabular}{lcccccccc}
\hline $\begin{array}{l}\text { Sample } \\
\text { No }\end{array}$ & $\begin{array}{c}\text { Ratio of } \\
\text { small } \\
\text { hole (\%) }\end{array}$ & $\begin{array}{c}\text { Mesopore } \\
\text { ratio (\%) }\end{array}$ & $\begin{array}{c}\text { Ratio of } \\
\text { large holes } \\
(\%)\end{array}$ & $\begin{array}{c}\text { Nuclear } \\
\text { magnetic total } \\
\text { porosity }(\%)\end{array}$ & $\begin{array}{c}\text { Bound } \\
\text { water } \\
\text { porosity }(\%)\end{array}$ & $\begin{array}{c}\text { Daily gas } \\
\text { production } \\
\left(\mathrm{m}^{3} / \mathrm{d}\right)\end{array}$ & $\begin{array}{c}\text { Daily water } \\
\text { production } \\
\left(\mathrm{m}^{3} / \mathrm{d}\right)\end{array}$ & $\begin{array}{c}\text { permeability } \\
\left(10^{-3} \mu \mathrm{m}^{2}\right)\end{array}$ \\
\hline No. 16 & $64.35 \%$ & $27.85 \%$ & $7.80 \%$ & $4.51 \%$ & $67.03 \%$ & 6495 & 0 & 0.160 \\
No. 26 & $14.46 \%$ & $43.75 \%$ & $41.78 \%$ & $7.61 \%$ & $30.70 \%$ & 2026 & 20 & 0.256 \\
No. 6 & $9.77 \%$ & $18.17 \%$ & $72.05 \%$ & $12.79 \%$ & $15.30 \%$ & 153679 & 4.8 & 30.441 \\
\hline
\end{tabular}

FIGURE 5: Relationship analysis between reservoir pore structure, permeability, and productivity in the study area. (a) No. 16. (b) No. 26. (c) No. 6.

where $P_{i}$ is the proportion of the $i$-th type of pores in the total pore, \%; $T_{2 i}$ is the $T_{2}$ relaxation time of the $i$-th type of pores, \%; $T_{E}$ is the echo interval time, \%; and $\varepsilon(j)$ is the random noise $(j=1,2,3, \ldots, n)$.

For water-wetted phase rocks, $T_{2}$ the transverse relaxation time can be simplified as follows $[13,36]$ :

$$
\frac{1}{T_{2}}=\rho_{2} \frac{S}{V}=F_{s} \frac{\rho_{2}}{r_{\text {por }}}
$$

where $\rho_{2}$ is the relaxation rate of rock surface, $\mu \mathrm{m} / \mathrm{ms} ;(S / V)$ is the pore specific surface area, $\mu \mathrm{m}^{-1} ; r_{\text {por }}$ is the pore radius, $\mu \mathrm{m}$; and $F_{s}$ is the dimensionless geometry factor of pores (3 for spherical pores and 2 for cylindrical pores).
The core capillary pressure curve of rock samples was obtained from the high-pressure mercury injection experiments. After applying pressure to mercury, when the mercury pressure was equal to the capillary pressure of the pore throat, mercury could overcome the resistance to enter the pore. The capillary pressure curve of the experimental rock core was obtained with the pore volume percentage of mercury and the corresponding pressure. The pseudo-capillary pressure curve is calculated using equation (3) under the condition of known $T_{2}$ distribution. The envelope area ratios of the measured mercury injection curve and the pseudo-capillary pressure curve at different pore sizes on both sides of the initial value of the large-small pore size boundary were respectively 


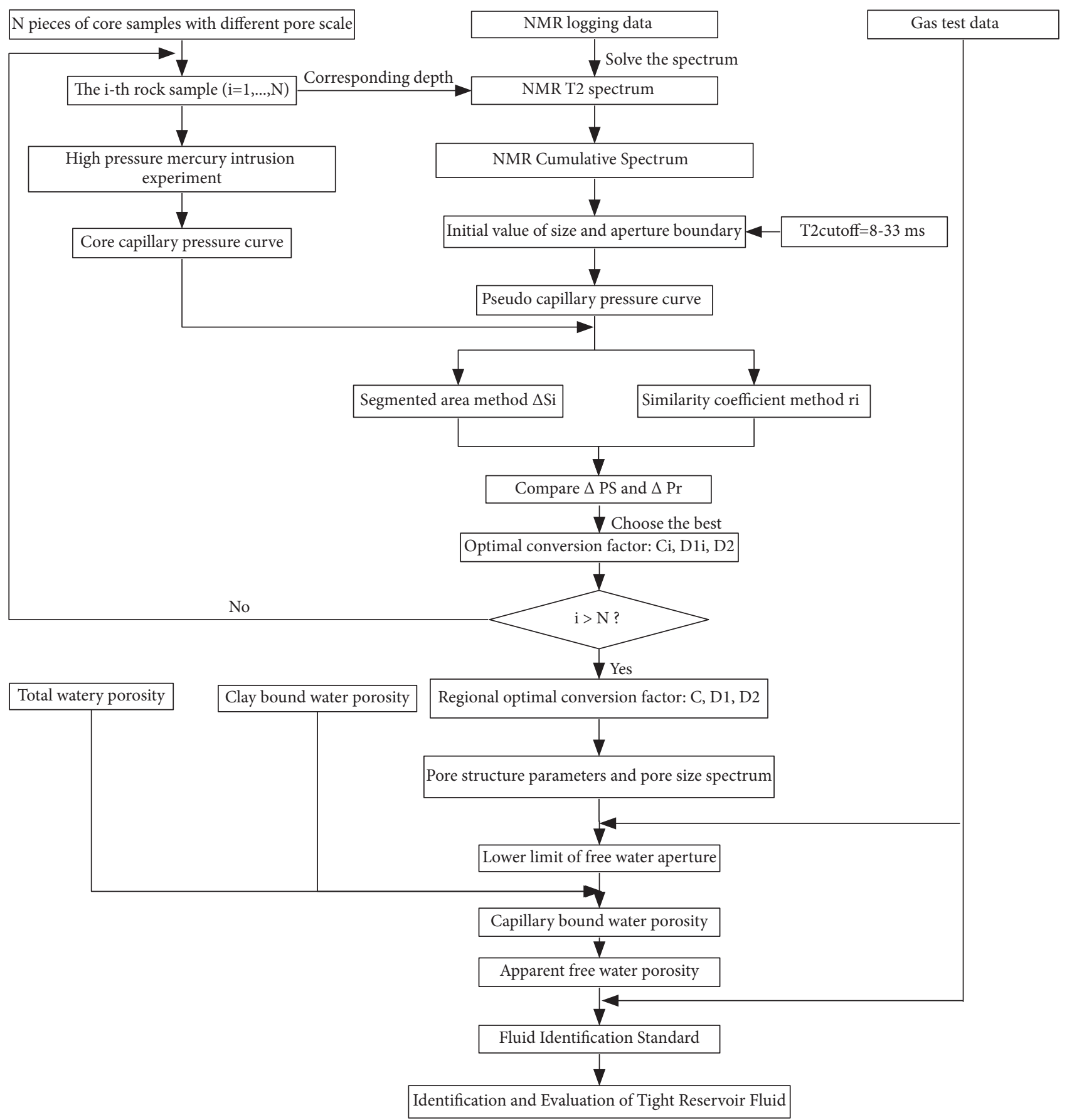

FIGURE 6: Flow chart of the discrimination of fluid properties with free water porosity. 
calculated as the longitudinal scale conversion coefficients of the large and small pore size scales [11-13].

$$
\begin{aligned}
& p_{c}=C \cdot \frac{1}{T_{2}}, \\
& D 1=\frac{\sum_{j=M 1}^{N 1} S_{H g, j}}{\sum_{i=1}^{M} A_{m, i}}, \\
& D 2=\frac{\sum_{j=1}^{M 1} S_{H g, j}}{\sum_{i=M}^{N} A_{m, i}},
\end{aligned}
$$

where $p_{c}$ is the mercury inlet pressure, MPa; $C$ is the dimensionless conversion coefficient between capillary pressure curve and $T_{2}$ spectrum; $D 1$ is the dimensionless conversion coefficient of longitudinal small aperture part; $D 2$ is the conversion coefficient of longitudinal large aperture part; $S_{H g, j}$ is the mercury saturation increment of the $j$-th component of the mercury injection curve, \%; N1 is the total number of components of mercury injection curve; $N$ is the total number of components of the pseudo-capillary pressure curve after transverse scale conversion of $T_{2}$ spectrum; $A_{m, i}$ is the amplitude of the $i$-th component of the pseudo-capillary pressure curve after transverse scale conversion from $T_{2}$ spectrum, \%; $M 1$ is the number of mercury injection components corresponding to the inflection point of aperture size boundary; $M$ is the component number of the pseudocapillary pressure curve after transverse scale conversion of $T_{2}$ spectrum corresponding to the inflection point of aperture size boundary; and $T_{2 \text { cuoff }}$ is the $T_{2}$ cutoff value obtained through core centrifugation experiment. A point is obtained from the sum of $T_{2}$ distribution amplitude of rock sample before centrifugation, so that the sum of amplitude of each point on the left side of the point is equal to the sum of $T_{2}$ distribution amplitude after centrifugation. The obtained point is taken as the $T_{2}$ cutoff value point $[12,37]$.

The sectional area method (6) and correlation coefficient method (7) were used to calculate the area difference and curve correlation coefficient between the core capillary pressure curve and the pseudo-capillary pressure curve, respectively. The iterative least-square method was used to automatically iteratively search the $T_{2}$ spectrum corresponding to the minimum area difference and the maximum correlation coefficient, and the conversion coefficients $C, D 1$, and $D 2$ of the pseudo-capillary pressure curve were then retrieved [13]:

$$
\begin{gathered}
\int_{P_{\min }}^{P_{\max }}\left[S_{H_{g}}(P)-S_{H_{g}}\left(P_{c}\right)\right] d_{P} \longrightarrow \min , \\
\frac{\sum\left[S_{H_{g}}(P)-S_{P}\right]\left[S_{H_{g}}\left(P_{c}\right)-S_{P_{c}}\right]}{\sqrt{n \cdot S_{H_{g}}(P)^{2}-\left[\sum S_{H_{g}}(P)\right]^{2}} \cdot \sqrt{n \cdot S_{H_{g}}\left(P_{c}\right)^{2}-\left[\sum S_{H_{g}}\left(P_{c}\right)\right]^{2}}} \longrightarrow \max ,
\end{gathered}
$$

where $S_{H_{g}}(P)$ is the reverse cumulative mercury saturation of $T_{2}$ spectrum, \%; $S_{H_{g}}\left(P_{c}\right)$ is the mercury saturation measured experimentally, $\% ; S_{P}$ is the mean value of discrete points of cumulative mercury inlet saturation as a function of mercury displacement pressure, \%; and $S_{P_{c}}$ is the mean value of discrete points of mercury injection saturation as a function of mercury displacement pressure obtained from core experiments, $\%$.
For each core, the optimal conversion coefficient iterated by the sectional area method and the correlation coefficient method corresponds to the pseudo-capillary pressure curve. The pseudo-capillary pressure curve is compared with the core capillary pressure curve, and the absolute errors $\Delta P_{S}$ and $\Delta P_{r}$ of the two curves are calculated. The sectional area method or the correlation coefficient method is selected for each rock sample based on 
absolute errors. The average value of $W$ group conversion coefficients with the smallest absolute error is taken as the regional optimal conversion coefficient.

$$
\begin{aligned}
& \Delta P_{S}=\left|\frac{P_{i s}-P_{i \text { core }}}{P_{i s}}\right| \cdot 100, \\
& \Delta P_{r}=\left|\frac{P_{i r}-P_{i \text { core }}}{P_{i r}}\right| \cdot 100,
\end{aligned}
$$

where $\Delta P_{S}$ and $\Delta P_{S}$ are the absolute errors between the pseudo-capillary pressure curve and the core capillary pressure curve respectively inversed by the sectional area method and the correlation coefficient method, \%; $P_{i s}$ and $P_{i r}$ are the proportion of the $i$-th type of pores in the total pores in the pseudo-capillary pressure curve respectively inversed by the sectional area method and the correlation coefficient method, \%; and $P_{i \text { core }}$ is the proportion of the $i$-th type of pores in the total pores in the capillary pressure curve measured by core experiments, $\%$.

The pseudo-capillary pressure curve is inversed with the regional optimal conversion coefficients $C, D 1$, and $D 2$, and the pore structure parameters are inversed with the pseudocapillary pressure curve.

The maximum throat radius $r_{\max }$ is calculated as follows [13]:

$$
r_{\max }=\frac{r(i) \Delta S_{H g}(i)+r(i-1) \Delta S_{H g}(i-1)}{S_{H g}(i)+\Delta S_{H g}(i-1)} \Delta S_{H g}(i),
$$

where $\Delta S_{H g}(i)$ is the mercury saturation of the $i$-th component of the pseudo-capillary pressure curve, $\% ; S_{H g}(i)$ is the cumulative mercury saturation of the $i$-th component of the pseudo-capillary pressure curve, $\%$; and $r(i)$ is the $i$-th throat radius component, $\mu \mathrm{m}$.

The displacement pressure $p_{\text {th }}$ is calculated as

$$
p_{\text {th }}=\frac{0.735}{r_{\max }} \text {. }
$$

The calculation formula of median pressure $p_{50}$ is

$$
p_{50}=\frac{p_{c}(i+1)-p_{c}(i)}{S_{H g}(i+1)-S_{H g}(i)}\left[50-S_{H g}(i)\right]+p_{c}(i) \text {. }
$$

The calculation formula of median radius $r_{50}$ is

$$
r_{50}=\frac{0.735}{p_{50}} \text {. }
$$

NMR total porosity $\left(\phi_{t}\right)$ is defined as the sum of porosity of all $T_{2}$ components $\left(\phi_{i}\right)$ :

$$
\phi_{t}=\sum \phi_{i}
$$

The calculation formula of clay-bound water porosity is

$$
\phi_{e}=\sum_{T_{2}>T_{2 \text { clay }}} \phi_{i}, \phi_{c b w}=\phi_{t}-\phi_{e}
$$

where $\phi_{e}$ is the effective porosity and defined as the total porosity minus the bound water porosity of clay; and $T_{2 \text { clay }}$ is the boundary value between capillary pores and clay pores.

\subsection{Calculation of Apparent Free Water Porosity and Construction of Fluid Identification Standard}

4.2.1. Determination of the Lower Limit of Free Water Pore Diameter. A crossplot was prepared with nuclear magnetic porosity, nuclear magnetic maximum pore throat radius, and gas test data to determine the lower limit of free water pore diameter. Assuming that only bound fluid exists under this lower limit, the clay-bound water porosity is inversely calculated with nuclear magnetic resonance logging data based on this lower limit.

Figure 7 shows an example of crossplot analysis of NMR porosity, NMR maximum pore throat radius, and gas test data including 254 gas test data of wells Li40, Li57, Li55, and Li59 in the study area. The crossplot results showed that the gas reservoir data were mainly distributed in the area with $R>0.2 \mu \mathrm{m}$. Therefore, it is assumed that the pore space with the throat radius less than $0.2 \mu \mathrm{m}$ only contains bound fluid and $R=0.2 \mu \mathrm{m}$ is taken as the lower limit of free water pore diameter. In the lower right part of the crossplot, the porosity is relatively large and the corresponding pore throat radius is relatively small. The gas test showed that it was mainly a gas-water layer.

4.2.2. Calculation Model of Apparent Free Water Porosity. Firstly, water saturation $S_{w}$ is calculated by the Archie formula and the total water porosity $\phi_{w}$ is calculated from the total porosity of NMR logging data (equation (13)). Then, clay-bound water porosity $\phi_{c b w}$ is inversed based on the optimal conversion coefficient found with NMR logging data to calculate capillary-bound water porosity $\phi_{b v i}$ according to the determined lower limit of free water pore diameter. Finally, apparent free water porosity $\left(\phi_{f f w}\right)$ can be calculated using equation (17):

$$
\begin{gathered}
\phi_{w}=\phi_{t} \cdot S_{w}, \\
\phi_{f f w}=\phi_{w}-\phi_{b v i}-\phi_{c b w} .
\end{gathered}
$$

4.2.3. Establishment of Fluid Criteria. Based on the nuclear magnetic apparent free water porosity calculated by the model, a crossplot was made with the original formation resistivity and gas test data to determine the identification standard of fluid types. Figure 8 shows the subdivision standard of the study area: gas layer (apparent free water porosity $\left.\phi_{f f w}<1.0\right)$, gas-water layer $\left(1.0 \leq \phi_{f f w} \leq 2.0\right)$, and water layer $\left(\phi_{f f w}>2.0\right)$.

\section{Application Example and Analysis Results}

5.1. Calibration of Model Core Experimental Data. The highpressure mercury injection experimental data of 4 rock samples of Well L57 and 3 rock samples of Well L59 in the study area were collected. After the least-square automatic iteration and the calibration with the mercury injection test data, the conversion coefficients were determined as $C=8.27(8.1 \sim 8.6), D 1=7.27$, and $D 2=9.85$. Figure 9 shows the core calibration results of Well L57, and 


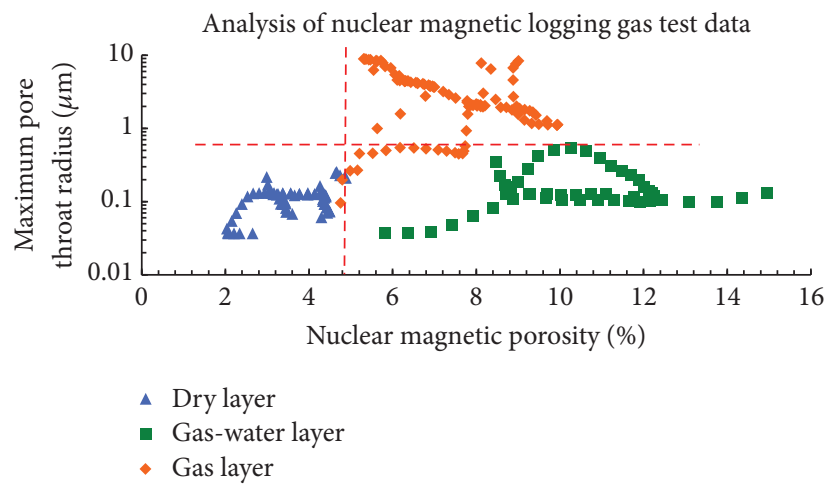

FIgURE 7: Crossplot of maximum pore throat radius and porosity based on NMR.

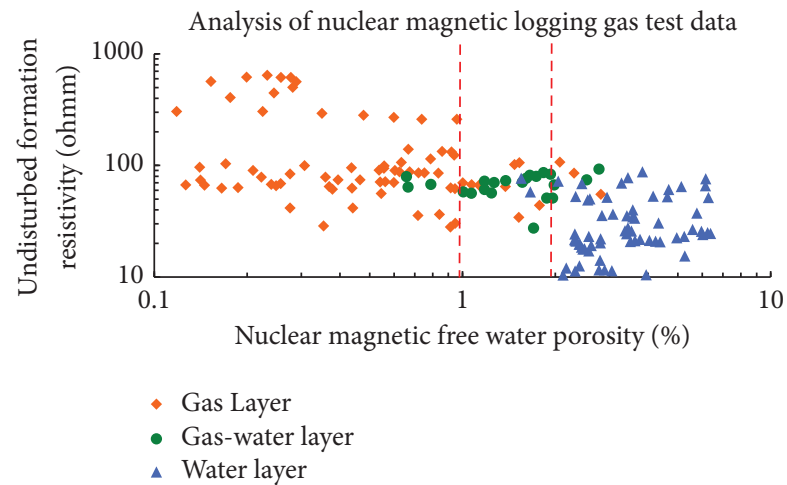

FIGURE 8: Crossplot of NMR-based free water porosity and undisturbed formation resistivity.

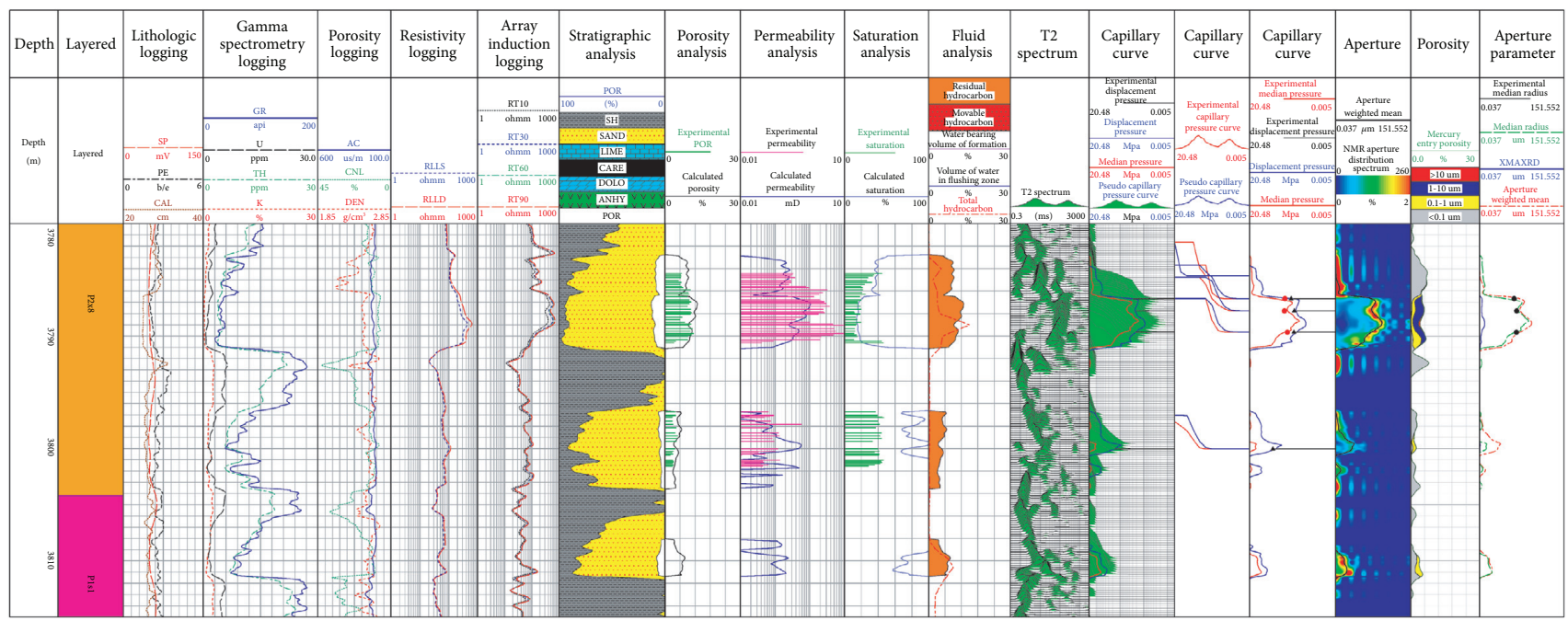

FIgURE 9: Calibration diagram of NMR aperture spectrum parameters of Well L57.

Figure 10 shows the core calibration results of Well L59. After core calibration, the pore structure parameters inversed by the calibrated model were compared with the core mercury injection experimental data. The correlation coefficients of median pressure (Figure 11(a)), displacement pressure (Figure 11(b)), and median radius (Figure 11(c)) are between 0.925 and 0.989 and proved the reliability of the inversion model.
5.2. Fluid Discrimination and Comprehensive Evaluation of Tight Sandstone Reservoirs. The established fluid discrimination model based on apparent free water porosity was used to identify the gas and water layers in Well Li40 in the study area. The result diagram is shown in Figure 12. The 9th channel shown in Figure 12 is the original interpretation conclusion of fluid identification according to the conventional curve crossplot method, whereas the 8th channel is the 


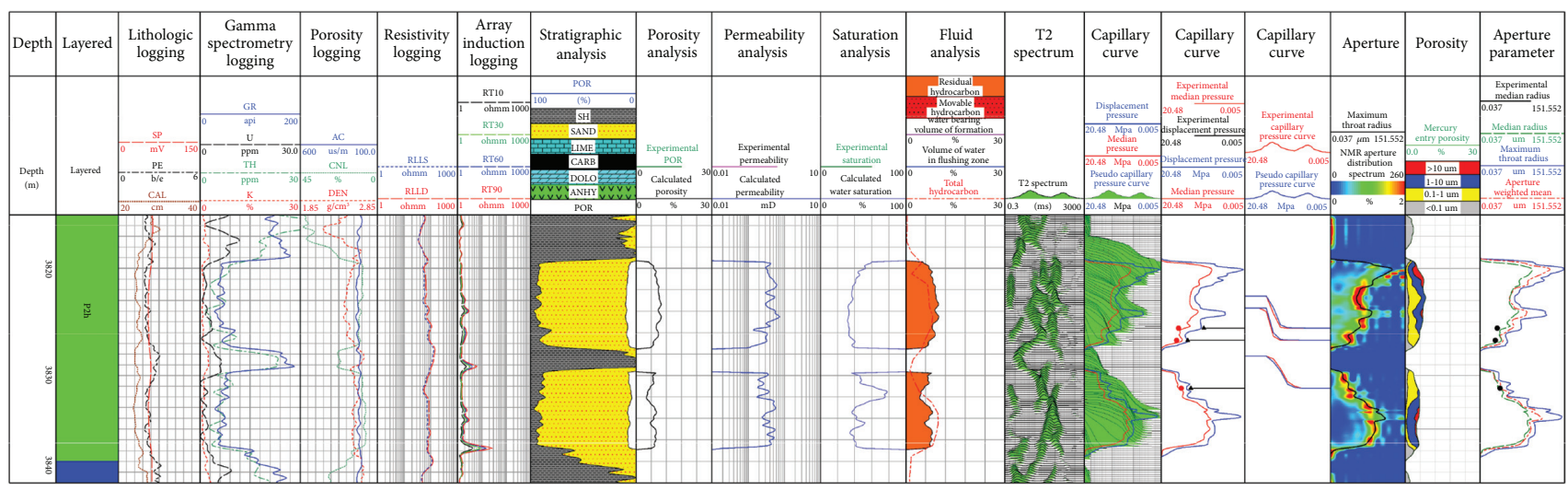

FIGURE 10: Calibration diagram of NMR aperture spectrum parameters of Well L59.

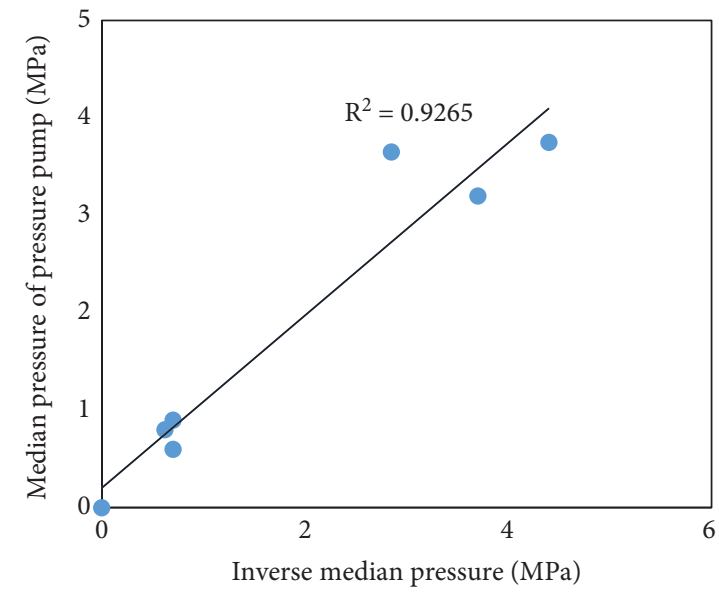

(a)

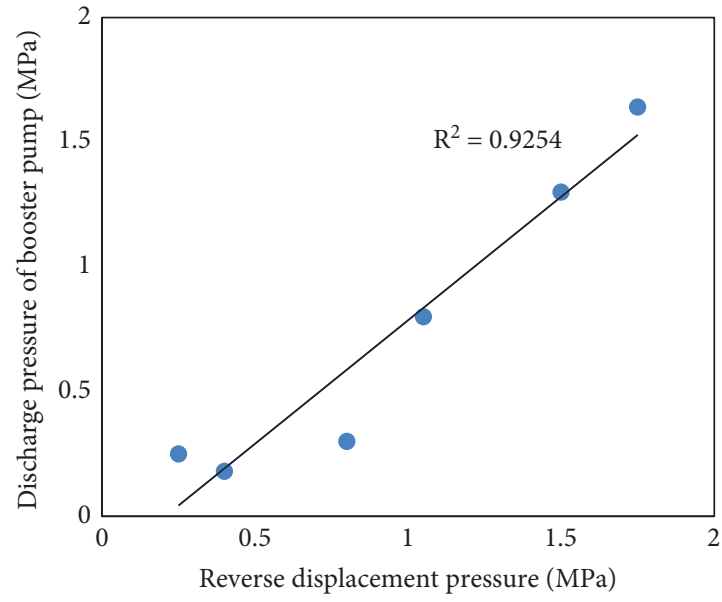

(b)

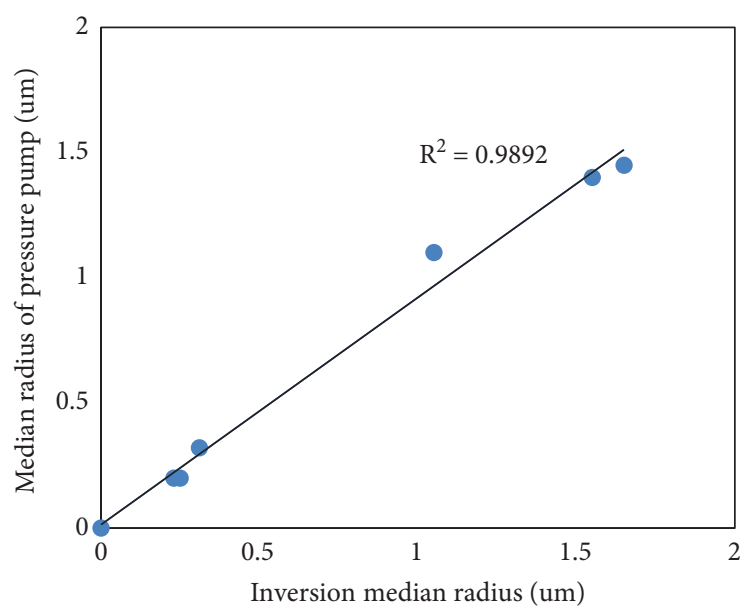

(c)

FIGURE 11: Comparative analysis of pore structure parameters inversed with NMR data and core mercury injection experimental data. (a) Median pressure. (b) Displacement pressure. (c) Median radius.

new interpretation conclusion based on the free water porosity curve calculated by the model in this paper. The 7th channel is the nuclear magnetic $T_{2}$ spectrum, and the sixth channel is the pseudo-capillary pressure curve obtained in this study. The fifth channel is the pore size spectrum of tight sandstone reservoirs obtained by inversion, and the fourth channel is the pore median radius obtained by inversion. The third channel is the pore size distribution curve obtained by inversion, and the second channel shows the porosity corresponding to different pore sizes. The first channel shows the porosity proportions of different pore fluids. Based on the crossplot of deep lateral resistivity and acoustic 


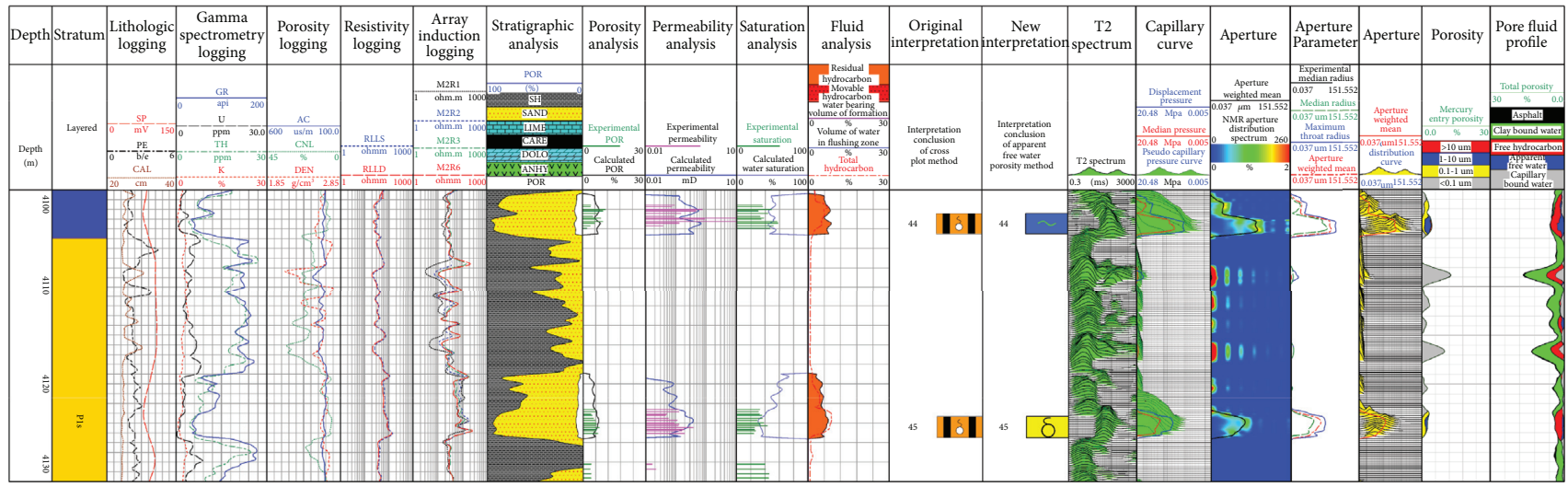

FIGURE 12: Interpretation results of Well Li40 based on NMR free water porosity.
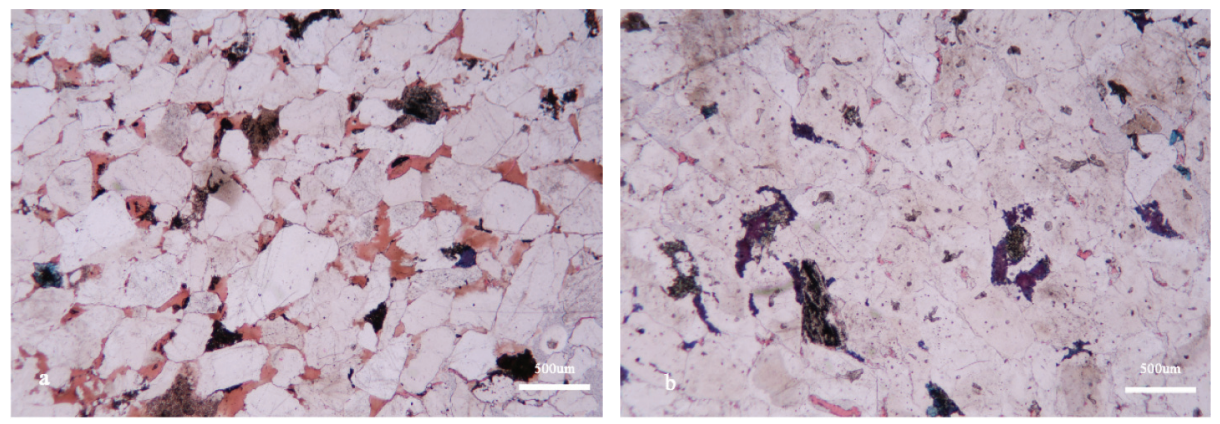

Figure 13: Microscope images of polished thin sections of the core samples obtained at different depths (4102 m (a) and $4103 \mathrm{~m}(\mathrm{~b})$ ) of Well Li40.

time difference, the No. 44 reservoir in Well Li40 was interpreted as a poor gas layer. However, the apparent free water porosity was greater than $2 \%$ and the average resistivity was greater than $30 \Omega \mathrm{m}$. Therefore, the reservoir was newly interpreted as a high-resistivity water layer. Based on the crossplot, the No. 46 reservoir was interpreted as a poor gas reservoir. However, the apparent free water porosity was less than $1 \%$, so the reservoir was newly interpreted as a gas reservoir. In order to verify whether the interpretation conclusions were correct, the two interpretation results were compared based on the gas test data, which were the most accurate discrimination basis for the fluid properties of reservoirs. According to the gas test data, the No. 44 reservoir did not produce gas and its daily water production was $14.4 \mathrm{~m}^{3} / \mathrm{d}$, suggesting that it was indeed a water layer. The high resistance might be ascribed to the poor pore connectivity and the high quartz content (Figure 13). The No. 46 reservoir had a daily gas production of $70342 \mathrm{~m}^{3} / \mathrm{d}$ and zero water production, suggesting that it was indeed a gas reservoir. The fluid discrimination model constructed based on apparent free water porosity in this paper accurately identified gas reservoirs and high-resistivity water layers, which were easily wrongly identified with the conventional logging curve crossplot method.

The interpretation results of Well Li46 are shown in Figure 14. The porosity and pore structure of the No. 40 reservoir (Figure 15(a)) was better than the No. 41 reservoir (Figure 15(b)). The No. 40 reservoir had larger pores and better connectivity (Figure 14), indicating that the quality of the No. 40 reservoir was better than the No. 41 reservoir. The apparent free water porosity at the bottom of the No. 40 reservoir was $1.0 \%$ to $2.0 \%$, so it was interpreted as the gaswater layer. In the No. 41 reservoir, apparent free water porosity was less than $1.0 \%$, so it was interpreted as a gas reservoir. According to the results of gas test data, daily gas production and daily water production of the No. 40 reservoir were, respectively, $71726 \mathrm{~m}^{3} / \mathrm{d}$ and $8.3 \mathrm{~m}^{3} / \mathrm{d}$, so it was interpreted as the gas-water layer. The No. 41 reservoir had a daily gas production of $52124 \mathrm{~m}^{3} / \mathrm{d}$ and zero water production, so it was interpreted as a gas reservoir. The interpretation conclusion based on the gas test data was consistent with the interpretation conclusion obtained with the apparent free water porosity and crossplot method. Therefore, the apparent free water porosity fluid identification model is more reliable.

In order to further verify the reliability of the model, the crossplot method of deep lateral resistivity and acoustic time difference and the apparent free water porosity method were used to identify the gas and water layers of the other 28 reservoirs in the study area, and the obtained results were compared with the interpretation conclusion of gas test data. The coincidence rate of the interpretation conclusion was statistically calculated. The coincidence rate of interpretation obtained with the crossplot method was $71.4 \%$. The coincidence rate of the interpretation results of the apparent free water porosity method reached $82.1 \%$ (Table 1 ). 


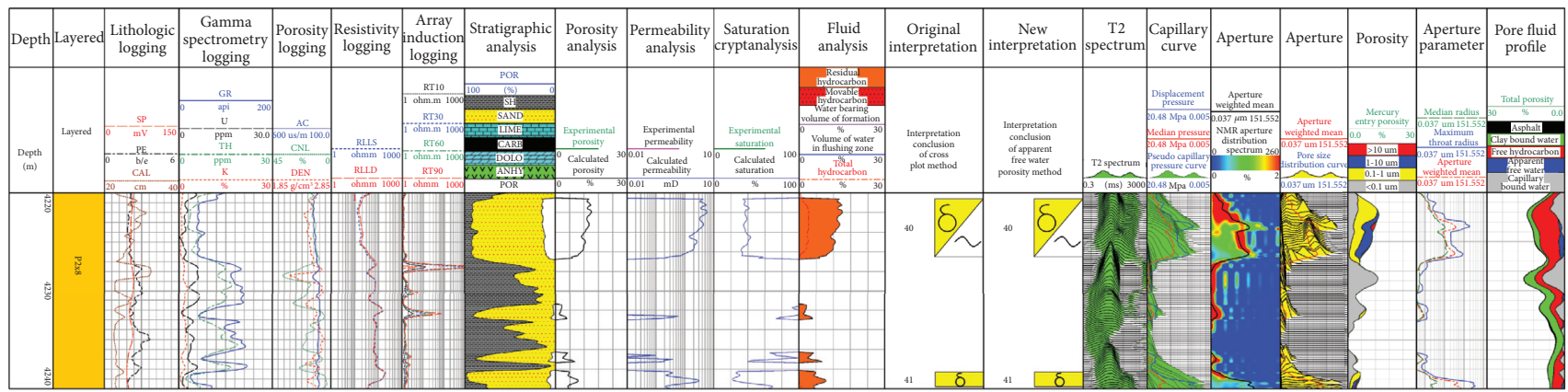

FIGURE 14: Interpretation results of Well Li46 based on NMR free water porosity.
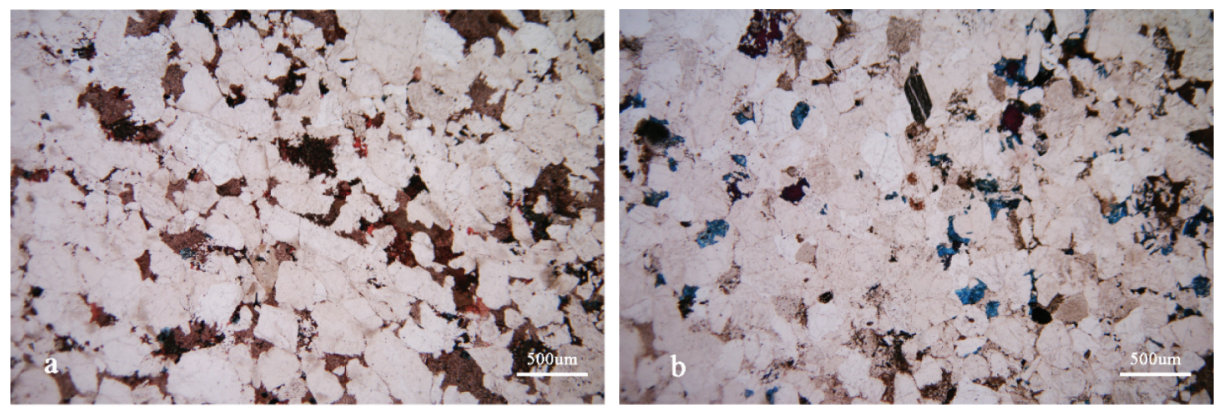

Figure 15: Microscope images of polished thin sections in the No. 40 reservoir at the depth of $4225 \mathrm{~m}$ (a) and the No. 43 reservoir at the depth of $4241 \mathrm{~m}$ (b) of Well Li46.

TABLE 1: Statistical table of the interpretation coincidence rate of the fluid discrimination model in the study area.

\begin{tabular}{|c|c|c|c|c|c|c|c|c|}
\hline \multirow[b]{2}{*}{ Well } & \multirow[b]{2}{*}{ Layer } & \multirow{2}{*}{$\begin{array}{l}\text { Free water } \\
\text { porosity } \\
\left(\varphi_{f f w}\right)\end{array}$} & \multirow{2}{*}{$\begin{array}{c}\text { Interpretation } \\
\text { conclusion of } \\
\text { crossplot method } \\
\text { (\%) }\end{array}$} & \multirow{2}{*}{$\begin{array}{c}\text { Interpretation } \\
\text { conclusion of } \\
\text { apparent free } \\
\text { water porosity } \\
\text { method }\end{array}$} & \multicolumn{2}{|c|}{ Test results } & \multirow{2}{*}{$\begin{array}{l}\text { Interpretation } \\
\text { coincidence of } \\
\text { crossplot method }\end{array}$} & \multirow{2}{*}{$\begin{array}{l}\text { Interpretation coincidence of } \\
\text { apparent free water porosity } \\
\text { method }\end{array}$} \\
\hline & & & & & $\begin{array}{c}\text { Gas } \\
\left(\mathrm{m}^{3} / \mathrm{d}\right)\end{array}$ & $\begin{array}{l}\text { Water } \\
\left(\mathrm{m}^{3} / \mathrm{d}\right)\end{array}$ & & \\
\hline E82 & $\begin{array}{c}\text { P2x8 } \\
\text { Upper }\end{array}$ & 0.41 & Gas layer & Gas layer & 22338 & 0 & $\sqrt{ }$ & $\sqrt{ }$ \\
\hline E51 & $\begin{array}{l}\text { part of } \\
\text { P2x8 }\end{array}$ & 0.22 & Gas layer & Gas layer & 43374 & 0 & $\sqrt{ }$ & $\sqrt{ }$ \\
\hline $\mathrm{E} 40$ & $\begin{array}{l}\text { P2x8 } \\
\text { Upper }\end{array}$ & 0.66 & Gas-water layer & Gas layer & 101195 & 7.5 & $\sqrt{ }$ & $\sqrt{ }$ \\
\hline E60 & $\begin{array}{l}\text { part of } \\
\mathrm{P} 2 \mathrm{x} 8\end{array}$ & 0.74 & Gas layer & Gas layer & 50591 & 1.8 & $\sqrt{ }$ & $\sqrt{ }$ \\
\hline E46 & $\mathrm{P} 2 \mathrm{x} 8$ & 0.18 & Gas layer & Gas layer & 57630 & 0 & $\sqrt{ }$ & $\sqrt{ }$ \\
\hline E80 & $\mathrm{P} 2 \mathrm{x} 8$ & 0.57 & Water layer & Gas layer & 24921 & 48 & $x$ & $\sqrt{ }$ \\
\hline E47 & $\begin{array}{l}\text { P2x8 } \\
\text { Lower }\end{array}$ & 0.65 & Gas layer & Gas layer & 22955 & 30 & $\sqrt{ }$ & $\sqrt{ }$ \\
\hline E70 & $\begin{array}{c}\text { part of } \\
\text { P2x8 }\end{array}$ & 1.24 & Gas layer & Gas-water layer & 2020 & 14.4 & $x$ & $\sqrt{ }$ \\
\hline E52 & $\begin{array}{l}\text { Upper } \\
\text { part of } \\
\mathrm{P} 2 \mathrm{x} 8\end{array}$ & 2.38 & Water layer & Water layer & 902 & 4.8 & $\sqrt{ }$ & $\sqrt{ }$ \\
\hline E84 & $\begin{array}{l}\text { Upper } \\
\text { part of } \\
\mathrm{P} 2 \mathrm{x} 8\end{array}$ & 1.76 & Water layer & Water layer & 534 & 23.5 & $\times$ & $x$ \\
\hline E78 & $\begin{array}{l}\text { P2x8 } \\
\text { Upper }\end{array}$ & 3.49 & Water layer & Water layer & 109 & 35 & $\sqrt{ }$ & $\sqrt{ }$ \\
\hline S175 & $\begin{array}{l}\text { part of } \\
\mathrm{P} 2 \times 8\end{array}$ & 0.86 & Gas layer & Gas layer & 113083 & 0 & $\sqrt{ }$ & $\sqrt{ }$ \\
\hline
\end{tabular}


TABLE 1: Continued.

\begin{tabular}{|c|c|c|c|c|c|c|c|c|}
\hline \multirow[b]{2}{*}{ Well } & \multirow[b]{2}{*}{ Layer } & \multirow{2}{*}{$\begin{array}{c}\text { Free water } \\
\text { porosity } \\
\left(\varphi_{f f w}\right)\end{array}$} & \multirow{2}{*}{$\begin{array}{c}\text { Interpretation } \\
\text { conclusion of } \\
\text { crossplot method } \\
(\%)\end{array}$} & \multirow{2}{*}{$\begin{array}{l}\text { Interpretation } \\
\text { conclusion of } \\
\text { apparent free } \\
\text { water porosity } \\
\text { method }\end{array}$} & \multicolumn{2}{|c|}{ Test results } & \multirow{2}{*}{$\begin{array}{l}\text { Interpretation } \\
\text { coincidence of } \\
\text { crossplot method }\end{array}$} & \multirow{2}{*}{$\begin{array}{l}\text { Interpretation coincidence of } \\
\text { apparent free water porosity } \\
\text { method }\end{array}$} \\
\hline & & & & & $\begin{array}{c}\text { Gas } \\
\left(\mathrm{m}^{3} / \mathrm{d}\right)\end{array}$ & $\begin{array}{l}\text { Water } \\
\left(\mathrm{m}^{3} / \mathrm{d}\right)\end{array}$ & & \\
\hline E58 & $\begin{array}{l}\text { Lower } \\
\text { part of } \\
\text { P2x8 }\end{array}$ & 0.67 & Gas layer & Gas layer & 25831 & 0 & $\sqrt{ }$ & $\sqrt{ }$ \\
\hline E71 & $\begin{array}{l}\text { Lower } \\
\text { part of } \\
\mathrm{P} 2 \mathrm{x} 8\end{array}$ & 0.75 & Gas layer & Gas layer & 41330 & 15 & $\sqrt{ }$ & $\sqrt{ }$ \\
\hline E67 & $\mathrm{P} 2 \mathrm{x} 8$ & 1.34 & Gas layer & Gas-water layer & 25473 & 24 & $x$ & $\sqrt{ }$ \\
\hline E83 & $\mathrm{P} 2 \mathrm{x} 8$ & 1.62 & Gas-water layer & Gas-water layer & 12412 & 21.6 & $\sqrt{ }$ & $\sqrt{ }$ \\
\hline E75 & $\begin{array}{l}\text { Lower } \\
\text { part of } \\
\mathrm{P} 2 \times 8\end{array}$ & 0.96 & Gas-water layer & Gas layer & 550 & 7.3 & $\sqrt{ }$ & $x$ \\
\hline
\end{tabular}

The above results showed that the apparent free water porosity-based fluid identification method proposed in this paper could identify the high-resistivity water layers in tight reservoirs in the study area to a certain degree and improve the accuracy of fluid identification in tight reservoirs in the study area.

\section{Conclusion}

In the study, the traditional fluid identification method was improved on the basis of previous studies. The improved method made good use of the segmented area method and the similarity comparison method and could automatically search for the optimal conversion coefficient and calculate the pseudo-capillary pressure curve in real time. Without the step of artificially dividing the reservoir quality, the method converted complex fluid identification parameters into a parameter of apparent free water porosity. To a certain degree, the improved method avoids the errors caused by subjective factors and has stronger applicability.

The correlation coefficient between the pore diameter parameters retrieved from the pseudo-capillary pressure curve calculated according to the optimal conversion coefficient, and the results measured by high-pressure mercury injection experiments was greater than 0.93 . The two curves were consistent in both large and small pores, and there was no bifurcation anomaly, which generally occurred in previous studies.

Based on the identification standard of gas and water layers in the nuclear magnetic free water porosity model, the high-resistivity water layer was largely identified and the coincidence rate of the interpretation results with final field test data was $10.7 \%$ higher than that of the conventional logging curve interpretation method.

\section{Data Availability}

These data are provided by China Changqing Oilfield. The data of Figures 3, 4, 7, and 8 are provided in "Figure Files." Because of the confidentiality of oilfield data, please forgive us for not providing more data.

\section{Conflicts of Interest}

The authors declare that they have no conflicts of interest.

\section{Acknowledgments}

The study was supported by the National Natural Science Foundation (Grant no. 41402118), Open Projects of National and Local Joint Engineering Research Center for Shale Gas Exploration and Development (Grant no. yyqktkfgjdflhgcyjzx-201901), and Chongqing Basic Research and Frontier Exploration Projects (Grant no. cstc2018jcyjax0503).

\section{References}

[1] M. Wang, H. M. Tang, H. X. Tang et al., "Impact of differential densification on the pore structure of tight gas sandstone: evidence from the Permian Shihezi and Shanxi formations, eastern Sulige gas field, Ordos Basin," Geofluids, vol. 2019, Article ID 4754601, 25 pages, 2019.

[2] N. Xu, S. P. Zhang, Y. S. Wang, and L. W. Qiu, "Diagenesis and pore formation in the upper paleozoic tight sandstone in the northern area of the Ordos basin," Acta Sedimentologica Sinica, vol. 1-16, 2021.

[3] H. C. Wang, D. S. Ren, Y. D. Hou, and H. Zhang, "Maincontrolling factor Analysis of the upper paleozoic gas-water distribution in northern Tianhuan depression," Special Oil \& Gas Reservoirs, vol. 25, no. 6, pp. 32-36, 2018.

[4] Y. Gao, S. Chen, F. X. Huang et al., "Micro-occurrence of formation water in tight sandstone gas reservoirs of low hydrocarbon generating intensity: case study of northern Tianhuan Depression in the Ordos Basin, NW China," Journal of Natural Gas Geoscience, vol. 6, no. 4, pp. 215-229, 2021.

[5] X. Li, Y. J. Shi, L. Wang, and S. Hu, "Logging ldentification and evaluation technique of tight sandstone gas reservoirs: taking sulige gas field as an example," Natural Gas Geoscience, vol. 24, no. 1, pp. 62-68, 2013.

[6] S. H. Zhang, J. Y. Zhou, G. Chen et al., "Identification method of high-resistivity water layer in Chang 8 member oil reservoirs in Huaqing area, Ordos Basin," China Petroleum Exploration, vol. 25, no. 6, pp. 118-128, 2020.

[7] Z. Liu, C. X. Ouyang, C. Q. Wang, D. L. Han, Q. Wu, and X. Gao, "Construct NMR capillary pressure curves by 
piecewise PowerFunction based on T2 cutoff values," Chinese Journal of Magnetic Resonance, vol. 36, no. 1, pp. 45-54, 2019.

[8] E. Sarris, E. Gravanis, and I. Ioannou, "A novel methodology for synthesizing the wetting capillary pressure curve of rocks through sorptivity data," Journal of Petroleum Science and Engineering, vol. 180, pp. 413-423, 2019.

[9] G. G. Pereira, "Fluid flow, relative permeabilities and capillary pressure curves through heterogeneous porous media," Applied Mathematical Modelling, vol. 75, pp. 481-493, 2019.

[10] A. Mirzaei-Paiaman and B. Ghanbarian, "A new methodology for grouping and averaging capillary pressure curves for reservoir models," Energy Geoscience, vol. 2, no. 1, pp. 52-62, 2021.

[11] W. Z. Shao, Y. J. Ding, Y. Liu, S. Q. Liu, Y. Q. Li, and J. H. Zhao, "The application of NMR log data in evaluation of reservoir pore structure," Well Logging Technology, vol. 33, no. 1, pp. 52-56, 2009.

[12] W. Liu, Z. X. Xiao, S. Y. Yang, and Y. J. Wang, "Comparative studies on methods of evaluation of reservoir pore structure by using NMR (nuclear magnetic resonance) Well logging data," Oil Geophysical Prospecting, vol. 44, no. 6, pp. 773-778, 2009.

[13] Y. J. Wang, L. Luo, X. E. Gan, G. Y. Yu, and B. D. Chen, "NMR logging pore structure evaluation method \&application for low porosity \& permeability reservoir," Well Logging Technology, vol. 39, no. 1, pp. 62-67, 2015.

[14] S. Hosseinzadeh, A. Kadkhodaie, and S. Yarmohammadi, "NMR derived capillary pressure and relative permeability curves as an aid in rock typing of carbonate reservoirs," Journal of Petroleum Science and Engineering, vol. 184, Article ID 106593, 2020.

[15] M. E. Gray, R. Daniel, J. Kaldi, and D. Kulikowski, "Generating pseudo-capillary pressure curves from nuclear magnetic resonance (NMR) data: a case study from the Cooper Basin, Australia," Australian Journal of Earth Sciences, vol. 68, no. 1, pp. 83-98, 2021.

[16] R. T. Akhmetov, V. V. Mukhametshin, and L. S. Kuleshova, "Simulation of the absolute permeability based on the capillary pressure curves using the dumbbell model," Journal of Physics: Conference Series, vol. 1333, no. 3, Article ID 32001, 2019.

[17] F. D. Zhang, J. Li, G. Q. Wei et al., "Formation mechanism of tight sandstone gas in areas of low hydrocarbon generation intensity: a case study of the Upper Paleozoic in north Tianhuan depression in Ordos Basin, NW China," Petroleum Exploration and Development Online, vol. 45, no. 1, pp. 78-87, 2018.

[18] Z. Qiu, D. Song, L. Zhang et al., "The geochemical and pore characteristics of a typical marine-continental transitional gas shale: a case study of the Permian Shanxi Formation on the eastern margin of the Ordos Basin," Energy Reports, vol. 7, pp. 3726-3736, 2021.

[19] G. T. Wang, G. Ji, L. H. Cheng et al., "The main controlling factors of gas and water distribution in western sulige gas field, Ordos basin," Xinjing Petroleum Geology, vol. 33, no. 6, pp. 657-659, 2012.

[20] Q. Hao, Z. G. Zhang, F. G. Jin et al., "Fine description of microscopic features of low-premeanility tight sandstone reservoir, Su 120 block, Sulige gasfield," Natural Gas Exploration and Developmen, vol. 37, no. 3, pp. 5-9, 2014.
[21] Z. S. Zhang, X. J. Wang, L. Y. Feng, Y. F. Li, M. Fu, and K. Wang, "Genetic analysis and ldentification of yanchang 8 high-resistivity water layer in huaqing Area,Ordos basin," Northwest Geology, vol. 53, no. 2, pp. 244-252, 2020.

[22] B. Bera, S. K. Mitra, and D. Vick, "Understanding the micro structure of Berea Sandstone by the simultaneous use of micro-computed tomography (micro-CT) and focused ion beam-scanning electron microscopy (FIB-SEM)," Micron, vol. 42, no. 5, pp. 412-418, 2010.

[23] D. F. Zhao, Y. H. Guo, X. Mao et al., "Characteristics of macro-nanopores in anthracite coal based on mercury injection, nitrogen adsorption and FE-SEM," Journal of Coal, vol. 42, no. 6, pp. 1517-1526, 2017.

[24] B. G. Isabelle and S. Alexander, "Determination of the exact microporous volume and BET surface area in hierarchical ZSM-5," Journal of Physical Chemistry C, vol. 123, no. 7, pp. 235-4242, 2019.

[25] Z. Q. Wei, D. Xia, J. L. Jiang et al., "Microstructure of silver nanopowders," Rare Metal Materials and Engineering, vol. 36, no. 9, pp. 1677-1680, 2007.

[26] B. Liu, L. Bai, Y. Chi, R. Jia, X. Fu, and L. Yang, "Geochemical characterization and quantitative evaluation of shale oil reservoir by two-dimensional nuclear magnetic resonance and quantitative grain fluorescence on extract: a case study from the Qingshankou Formation in Southern Songliao Basin, northeast China," Marine and Petroleum Geology, vol. 109, pp. 561-573, 2019.

[27] S. Mohamed, E. Sharawy, and R. Gamal, "Impacts of petrophysical properties of sandstone reservoirs on their irreducible water saturation: implication and prediction," Journal of African Earth Sciences, vol. 156, pp. 118-132, 2019.

[28] B. Liu, X. W. Jiang, L. H. Bai, and R. Lu, "Investigation of oil and water migrations in lacustrine oil shales using $20 \mathrm{MHz} 2 \mathrm{D}$ NMR relaxometry techniques," Petroleum Science, 2021, In press.

[29] C. Minh, V. Jain, R. Griffiths, and D. Maggs, "NMR T2 fluids substitution," in Proceedings of the SPWLA 57th Annual Logging Symposium, pp. 1-12, Reykjavik, Iceland, June 2016.

[30] J. Hofman, W. Slijkermail, W. Looyestijn, and Y. Volokitin, "Constructing capillary pressure curves from NMR log data in the presence of hydrocarbons," in Proceedings of the SPWLA 40th Annual Logging Symposium, Oslo, Norway, May 1999.

[31] F. Mirzaee, E. Solhi, and S. Naserifar, "Approximate solution of stochastic Volterra integro-differential equations by using moving least squares scheme and spectral collocation method," Applied Mathematics and Computation, vol. 410, pp. 1-10, 2021.

[32] J. Yang, J. Leng, L. Qiao, L. Wang, and J. Ding, "Parameter prediction of water imbibition in unsaturated shales using the NMR method," Geofluids, vol. 2019, Article ID 4254159, 9 pages, 2019.

[33] G. Su, X. Zhou, L. Wang, Y. Wang, and S. Nie, "An inversion method of 2D NMR relaxation spectra in low fields based on LSQR and L-curve," Journal of Magnetic Resonance, vol. 265, pp. 146-152, 2016.

[34] Z. B. Gu and W. Liu, "Two dimensional NMR spectrum inversion," Journal of spectroscopy, vol. 24, no. 3, pp. 311-319, 2007. 
[35] R. H. Xie, L. Z. Xiao, J. Liu, and D. Keh-Jim, "NMR multi echo string joint inversion method," Journal of Geophysics, vol. 52, no. 11, pp. 2913-2919, 2009.

[36] M. Tan, Y. Zou, and C. Zhou, "A new inversion method for (T2, D) 2D NMR logging and fluid typing," Computers \& Geosciences, vol. 51, pp. 366-380, 2013.

[37] M. N. Testamanti and R. Rezaee, "Determination of NMR T2 cut-off for clay bound water in shales: a case study of Carynginia Formation, Perth Basin, Western Australia," Journal of Petroleum Science and Engineering, vol. 149, pp. 497-503, 2017. 